\title{
Human rights: the law must be accessible close at
} hand

Two recent cases, one of which I have personal experience and the other that I have read about, led me to raise problems which must arise as the criteria for informed consent and sectioning get stricter.

'How would you handle this situation' I asked Charles. 'A 55-year-old woman was involved in car crash and received a blow on the neck. Afterwards she had severe impediment of speech with some weakness of the right arm but was otherwise more or less unscathed. By the end of the first week there were no signs of improvement. In the meanwhile minimally invasive investigations had revealed that the accident had uncovered pre-existing critical narrowing of the left main carotid artery. She was referred to the speech therapist who reported that not only did she have severe motor dysphasia but also sensory dysphasia to the extent of not being capable of giving informed consent.'

\section{'What did her medical advisers decide?'}

'They decided that if she could not give informed consent they could not go ahead with the operation despite the pleadings of her husband and family to do so'.

'How did they justify that? Did they not think beforehand or did they go ahead with the investigations because they regarded them as 'lesser' procedures?' he asked rhetorically, and then added 'What do you think they should have done when they got to that point?'

'I find it very difficult. There was clearly a very high danger of a spontaneous complete stroke. If it were me I would like to have been operated on.'

'This case raises two separate but related issues. Is full informed consent required for even the most minor procedure? Can you set a level above which informed consent is necessary to maintain a patient's autonomy?' He continued 'In this context was the patient unconscious at any time?'

'I don't know, but I don't think so' I replied ' Let's for the sake of argument accept that and assume that she was in the same condition when the minimally invasive investigations were done as she was later.'

\author{
'What were the investigations?'
}

'I presume a CT scan and a digital subtraction angiogram which involves only venous access' I replied.

'Are they really a whole order below more invasive angiography? There could not have been implied consent, to me only an acceptable principle with minor procedures in fully competent patients.'

'And what is your second question?'

'Should the permission be required for inaction as well as action where the latter is likely to be more beneficial to the patient?'

، "First do no harm"' I replied

'This is indeed a laudable objective cautioning against over-enthusiastic intervention but the down side is that it may induce complacency.'

'Fair enough' I said. 'Are you suggesting that the ethical implications of decisions to act and ought not to act are the same?'

'Yes, if one's efforts are guided at the best interest of the patient they must be, and in this case it would have been perfectly possible to get a quick answer from the court.'

'I thought you could only do that with children'

'A common misconception! Imagine if the patient had had a major stroke and then recovered sufficiently to sue. How would this argument stand up in court 'Although permission is needed to do something beneficial, it is not needed to stand by and allow preventable damage'?'

'Badly'

'Quite' he replied. 'Tell me about the other case?'

'A patient of mine developed cerebral metastases. He remained in physically good condition but became manic squandering all the family's assets. In the psychiatrist's opinion he was not 'sectionable' but he refused to sign the Power of Attorney. How would you handle that? 
'His wife should have applied to the Court of Protection'

'I knew you could do that but thought it was remote and took a long time. Indeed I believed she tried but it was too late.'

'It is true that the procedure does take time. I suppose it was all right in the past, when a quiet word to the bank manager possibly backed by her GP, would have ensured that the cheques were not honoured in the meanwhile.'
'But banks cannot do that sort of thing nowadays'

'No they can't. Both cases illustrate the danger that people may suffer from increasingly strict interpretation of their human rights. As you know I have my misgivings, but this trend is here to stay. Both sceptic and enthusiast must accept the consequences. These examples show the importance of making clinicians aware of the possibilities, and the need for rapid and local recourse to the courts including the Court of Protection.'

Coemgenus 